\title{
Pengembangan Kawasan Wisata Prigi Berdasarkan Konsep Tourism Branding
}

\author{
Jhon Jhohan Putra K.D, Hertiari Idajati \\ Departemen Perencanaan Wilayah dan Kota, Fakultas Teknik Sipil dan Perencanaan, Institut \\ Teknologi Sepuluh Nopember (ITS) \\ e-mail: ide_archits@yahoo.com
}

\begin{abstract}
Abstrak-Berdasarkan RTRW Kabupaten Trenggalek tahun 2012-2032 jumlah kawasan wisata yang ada di Trenggalek sebanyak 23 kawasan yang terdiri atas 9 kawasan pariwisata dan 14 kawasan pariwisata alam. Salah satunya adalah kawasan wisata Prigi yang didalamnya termasuk 2 pantai yaitu Pantai Prigi dan Pantai Karanggongso, yang terletak di Kecamatan Watulimo, Kabupaten Trenggalek merupakan wisata unggulan yang mempunyai banyak potensi dan daya tarik yang dapat menarik wisatawan. Akan tetapi upaya pengenalan kawasan wisata prigi sebagai destinasi unggulan Kabupaten Trenggalek masih terbatas. Di tingkat kabupaten, Trenggalek belum memiliki slogan maupun kampanye kreatif kepariwisataan. Tahapan pertama penelitian ini adalah mengidentifikasi potensi dan masalah kawasan wisata prigi berdasarkan konsep tourism branding menggunakan content analysis. Kemudian merumuskan arahan pengembangan kawasan wisata prigi berdasarkan konsep tourism branding menggunakan analisis deskriptif komparatif. Hasil dari penelitian ini berupa arahan pengembangan berdasarkan brand personality, brand positioning, dan brand identififer.
\end{abstract}

Kata Kunci-Tourism branding. Pengembangan kawasan

\section{PENDAHULUAN}

$\mathrm{K}$ ABUPATEN Trenggalek yang terletak di bagian selatan Pulau Jawa adalah salah satu kabupaten di Jawa Timur yang memiliki potensi pariwisata yang tinggi, terutama pariwisata yang mengandalkan kenampakan alam. Kondisi ini dipengaruhi oleh letak geografis Kabupaten Trenggalek yang berada pada daerah perbukitan dan pesisir. Jenis objek wisata yang mendominasi Kabupaten Trenggalek adalah pantai dan goa. Berdasarkan RTRW Kabupaten Trenggalek tahun 20122032, jumlah kawasan wisata yang telah ditetapkan berjumlah sebanyak 23 kawasan yang terdiri atas 9 kawasan pariwisata budaya dan 14 kawasan pariwisata alam. (RIPPDA Kabupaten Tenggalek).

Dalam skala wilayah yang lebih luas, kawasan wisata Prigi merupakan bagian dari Minapolitan Prigi yang berorientasi pada kegiatan perikanan tangkap. Keberadaan objek dan daya tarik wisata ini tentu dimanfaatkan oleh pemerintah daerah untuk meningkatkan perekonomian daerah Kabupaten Trenggalek. Pemerintah Kabupaten Trenggalek sebenarnya sudah mencanangkan untuk meningkatkan pendapatan asli daerah (PAD) dari sektor pariwisata. Pada tahun 2012 target kenaikan PAD asli daerah adalah sebesar Rp 14.000.000.000,00 dari Rp 63.000.000.000,00 pada tahun
2013 menjadi Rp 77.000.000.000,00.

Potensi dari Pantai Prigi dan Pantai Karanggongso dapat dikatakan serupa, meskipun masing-masing pantai memiliki ciri khasnya tersendiri. Pantai Prigi adalah wisata bahari dengan point of view dan berenang, sedangkan potensi dari Pantai Karanggongso dengan pasit putihnya mempunyai daya tarik yang meliputi berperahu, berenang, bananaboat dan poin of view.

Pada tahun 2012 jumlah pengunjung Pantai Prigi mencapai 72.846 orang, Karanggongso 245.640 orang. Pada tahun 2013 jumlah pengunjung Pantai Prigi mengalami peningkatan 88.374 orang sedangkan Karanggongso 288.165. Pada tahun 2014 jumlah pengunjung pantai Prigi 82.211 sedangkan untuk Karanggongso 337.180. Tahun 2015 jumlah pengunjung Pantai Prigi mencapai 90.251 sedangkan Karanggongso 358.590. Lalu pada tahun 2016 jumlah pengunjung Pantai Prigi 77.259 sedangkan Karanggongso 393.903 (Dinas Pariwisata dan Kebudayaan, 2017). Berdasarkan fakta tersebut dapat diketahui bahwa tingkat kunjungan antara Pantai Karanggongso dan Prigi terdapat kesenjangan, meskipun kedua pantai tersebut terletak dalam satu kawasan. Tren pengunjung di Karanggongso cenderung naik tiap tahunnya. Sedangkan untuk Pantai Prigi cenderung naik turun.

Selama ini upaya pengenalan kawasan wisata Prigi sebagai destinasi unggulan Kabupaten Trenggalek masih terbatas. Di tingkat kabupaten, Trenggalek belum memiliki slogan maupun kampanye kreatif kepariwisataan. Salah satu upaya yang dilakukan dalam berbagai keterbatasan adalah penyelenggaraan Prigi Fest. Perayaan ini pertama kali diselenggarakan pada tahun 2015. Agenda Prigi Fest pertama antar lain pameran UMKM (usaha mikro, kecil, dan menengah) milik nelayan, diskusi ekonomi kerakyatan, dan lomba desain miniatur kapal. Pada tahun 2016 perhelatan Prigi Fest kembali digelar untuk kedua kalinya dengan kegiatan serupa.

Oleh karena itu diperlukan identifikasi potensi dan masalah kawasan wisata prigi guna merumuskan arahan pengembangan kawasan wisata prigi.

\section{METODE PENELITIAN}

\section{A. Metode Pengumpulan Data}

Metode pengumpulan data yang digunakan dalam penelitian ini adalah survey primer dan survey sekunder. Survey primer bertujuan untuk melakukan wawancara dengan responden. 
Sedangkan survey sekunder bertujuan untuk mengumpulkan data-data instansional ataupun dokumen perencanaan pariwisata terkait.

\section{B. Variabel Penelitian}

Variabel penelitian merupakan hal yang menjadi objek pengamatan penelitian. Berikut merupakan tabel variabel dari penelitian ini :

Tabel 1.

Indikator, Variabel, dan Sub Variabel

\begin{tabular}{lll}
\hline \hline Indikator & Variabel & Sub Variabel \\
\hline Brand Personality & Daya Tarik & $\begin{array}{l}\text { Daya Tarik Alami } \\
\text { Daya Tarik Buatan } \\
\text { Daya Tarik Budaya }\end{array}$ \\
& & $\begin{array}{l}\text { Kedekatan dengan } \\
\text { ODTW lain }\end{array}$ \\
Brand Positioning & Linkage & $\begin{array}{l}\text { Keunikan yang berbeda } \\
\text { dengan ODTW lain }\end{array}$ \\
& Keunikan & Image \\
\hline Brand Identifier & Citra & \\
\hline \hline
\end{tabular}

Sumber : Hasil sintesa pustaka

\section{Mengidentifikasi potensi dan masalah di kawasan wisata prigi}

Untuk mengidentifikasi potensi dan masalah kawasan wisata prigi maka dilakukan content analysis. Fungsi dari content analysis sendiri adalah menggambarkan karakteristik komunikasi dengan mengajukan pertanyaan apa, bagaimana, dan kepada siapa pesan itu disampaikan. Sedangkan tahapan untuk content analysis dimulai dengan menentukan responden yang kompeten untuk digali informasinya, kemudian menentukan pertanyaan-pertanyaan, lalu mewawancari responden terkait pertanyaan-pertanyaan yang sudah disiapkan. Setelah wawancara selesai dan jawaban didapatkan, maka hasil wawancara ditranskripkan kemudian dilakukan coding, dalam coding dilakukan pencatatan konteks dan istilah-istilah yang penting. Kemudian, dilakukan klasifiaksi terhadap coding yang telah dilakukan. Klasifikasi dilakukan dengan melihat sejauh mana satuan makna berhubungan dengan tujuan penelitian.

\section{Merumuskan arahan pengembangan kawasan wisata prigi berdasarkan konsep tourism branding}

Dalam merumuskan arahan pengembangan kawasan wisata prigi berdasarkan konsep tourism branding maka digunakanlah analisis deskriptif komparatif. Analisis deskriptif komparatif ini meggunakan variabel, potensi dan masalah, serta best practice.

\section{HASIL DAN DISKUSI}

\section{A. Identifikasi potensi dan masalah kawasan wisata prigi berdasarkan konsep tourism branding}

Dalam melakukan proses analisis untuk mengidentifikasi potensi kawasan wisata prigi berdasarkan indicator dari tourism branding dilakukan in depth interview dan dianalisis menggunakan content analysis.

\begin{tabular}{lll}
\hline \hline \multicolumn{1}{c}{ Indikator } & \multicolumn{1}{c}{$\begin{array}{c}\text { Sub } \\
\text { Variabel }\end{array}$} & \multicolumn{1}{c}{ Potensi dan Masalahan } \\
\hline Brand & Daya Tarik & Potensi daya tarik alami yang ada adalah \\
Personality & Wisata & - berupa pemandangan alam point of view \\
& Alami & ombak yang kecil karena letak kawasan \\
& & wisata berada di teluk. \\
& & - Mempunyai pasir putih \\
& & - Ombak tenang \\
& & - Karang yang indah \\
& & Sedangkan untuk permasalahan yang ada \\
& & adalah, \\
& & kapal-kapal liar yang disandarkan dan \\
& & menghalangi view pemandangan indah \\
& & alam. \\
& & Tempaat snokling hanya di satu tempat.
\end{tabular}

Daya Tarik Potensi Daya tarik wisata buatan yang ada Wisata di kawasan wisata adalah

Buatan - sarana volley pantai,

- $\quad$ panggung 360 yang digunakan untuk spot foto maupun pagelaran seni dan budaya,

- fasilitas hiburan seperti banana boat dan berperahu

- $\quad$ rumah apung yang dapat digunakan untuk snorkling di kolam yang ada ditengah

- $\quad$ pusat kios-kios kerajinan masyarakat.

- Ada potensi penjualan ikan segar saat musim maret

- Ikan asap menjadi salah satu daya tarik pengunjung untuk datang

- Permasalahan Daya tarik wisata buatan yang ada di kawasan wisata adalah

- Rumah apung hanya di satu titik lokasi

- Kios-kios tersebut ada yang liar dan tanpa ijin

Daya Tarik Potensi Daya tarik budaya yang ada di Wisata kawasan wisata prigi adalah

Budaya - upacara petik laut dan larung semboyo yang diadakan setiap setahun sekali.

- ada Prigi fest yaitu acara pagelaran seni dan budaya yang juga berguna sebagai sarana promosi kawasan wisata prigi.

- Lomba kerajinan pembuatan kapal saat Prigi Fest

- Lomba peragaan busana batik saat Prigi Fest

- Permasalahan Daya tarik budaya yang ada di kawasan wisata prigi adalah

- Informasi kepada wisatawan terkait kegiatan-kegiatan yang ada di Prigi Fest perlu ditingkatkan

Brand Kede-katan Potensi yang ada adalah

Positioning dengan - lokasi kawasan wisata prigi sangat ODTW lain strategis dekat dengan ODTW lain. Dengan hal ini maka dapat dibuat paket wisata atau rute perjalanan.

Permasalahan yang ada adalah

- ODTW yang berdekatan juga merupakan wisata pantai

Keunikan Perbedaan kawasan wisata prigi dengan yang yang lain adalah

berbeda - Letaknya berdekatan dengan Pelabuhan dengan Perikanan Negeri prigi memungkinkan ODTW lain para wisatawan untuk mendapatkan ikan segar sebagai oleh-oleh maupun untuk dikonsumsi secara langsung dengan cara dibakar terlebih dahulu di kios-kios yang ada. 


\begin{tabular}{ll}
\hline \hline & pantainya yang luas dapat digunakan \\
& untuk berbagai macam kegiatan \\
& Mempunyai panggung 360, sedangkan \\
& ditempat lain tidak ada \\
& Mempunyai daya tarik wisata alam, \\
& wisata buatan dan wisata budaya, \\
& sedangkan jika dibandingkan dengan \\
& ODTW lain di lingkup Trenggalek \\
& hanya kawasan Prigi saja yang \\
& memilikinya. \\
Brand & Image kawasan wisata \\
Identifier & Pantai yang mempunyai pasir putih \\
& yang luas \\
& Prigi Fest yang sudah menjadi image \\
& daya tarik wisata dengan panggung 360 \\
& Wisata budaya yaitu upacara petik laut \\
& dan larung semboyo yang diadakan \\
& setiap setahun sekali. \\
& Ikan segar dan ikan asap yang menarik \\
& pengunjung datang \\
\hline \hline
\end{tabular}

\section{B. Arahan Pengembangan Kawasan Wisata Prigi}

\section{Berdasarakan konsep tourism destination branding}

Untuk dapat merumuskan arahan pengembangan kawasan wisata prigi maka digunakan analisis deskriptif komparatif. Dan diapat hasil seperti pada tabel berikut :

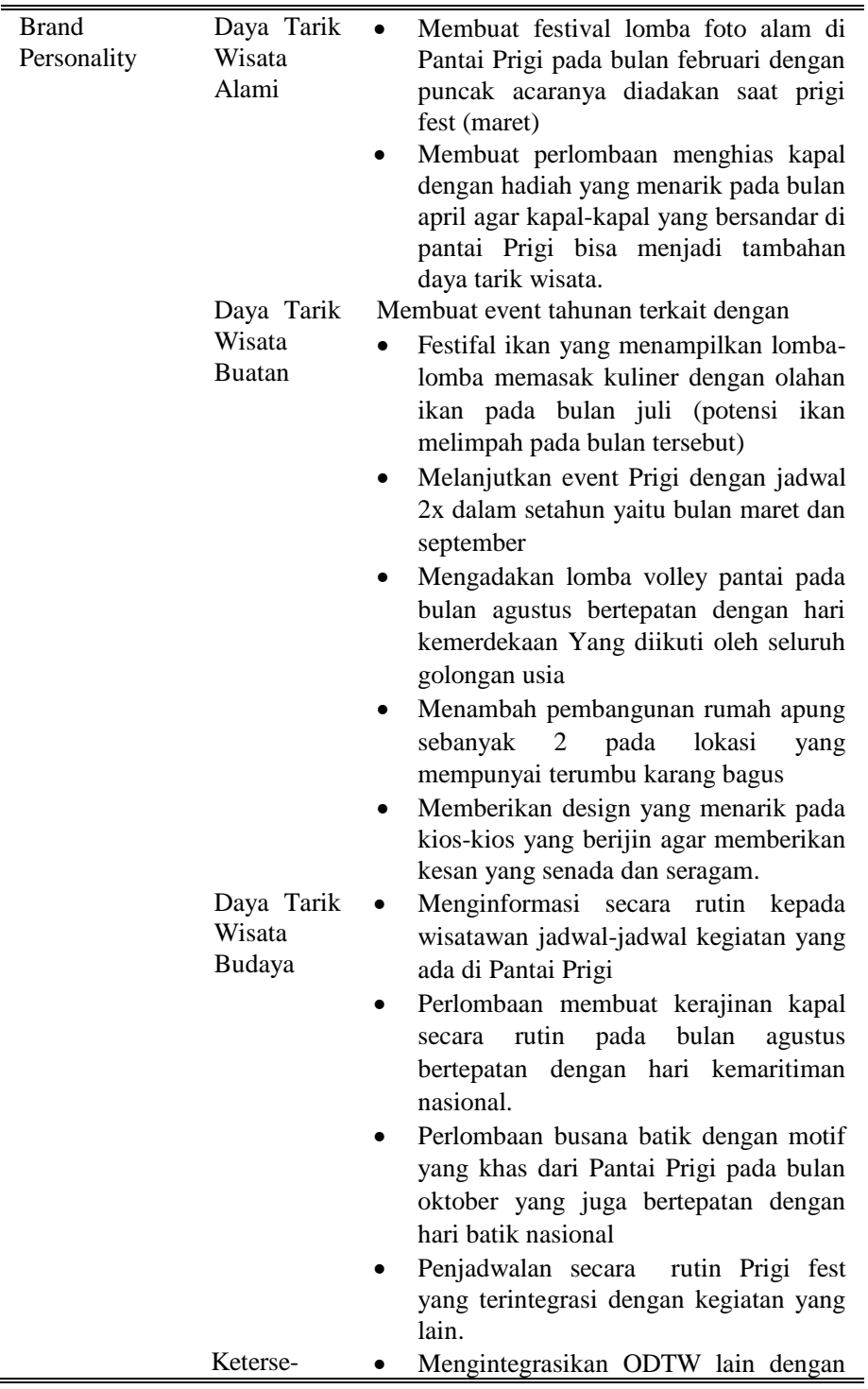

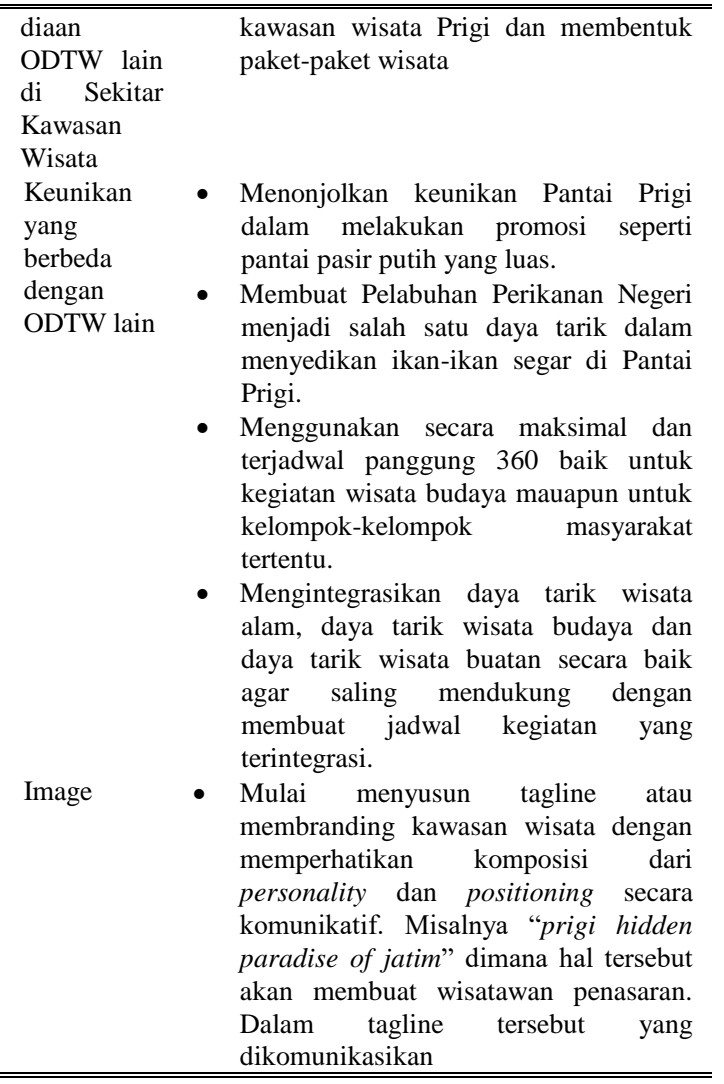

\section{KESIMPULAN}

Berdasarkan hasil analisis yang telah dilakukan terhadapat pengembangan kawasan wisata prigi berdasarkan konsep tourism branding maka dapat ditarik kesimpulan pengembangan kawasan wisata prigi diarahkan pada peningkatan intensitas even-even, kemudian mulai menginisiasi branding kawasan dengan mulai menyusun tagline berdasarkan ciri khas kawasan atau kabupaten Trenggalek, mengintegrasikan ODTW satu dengan yang lain, dan menambah dan meningkatkan daya tarik yang sudah ada.

\section{DAFTAR PUSTAKA}

[1] Joan C. Henderson. (2007). Uniquely Singapore? A Case Study In Destination Branding.

[2] Graham Hankinson. (2005). Destination Brand Images: A Business Tourism Perspective.

[3] Inskeep, Edward. (1991). Tourism Planning: An Integrated Dan Sustainable Development Approach, Van Nostrand Reinhold. New York. 